\title{
A ATUAÇÃo DE PSICÓlOGOS EM CONSELHOS TUTELARES
}

\author{
Vinicius Coscioni \\ Universidade Federal do Rio Grande do Sul \\ Edinete Maria Rosa \\ Universidade Federal do Espírito Santo
}

\author{
Sabrine Mantuan dos Santos Coutinho \\ Universidade Federal Fluminense - Campus de Campos de Goytacazes
}

Hildiceia dos Santos Affonso

Universidade Vila Velha/ES

Sílvia Helena Koller

Universidade Federal do Rio Grande do Sul

\begin{abstract}
Resumo
O objetivo deste ensaio teórico é sugerir diretrizes para a atuação de psicólogos no Conselho Tutelar (CT). Sua escrita encontra-se motivada pelo entendimento de que a inserção da psicologia no CT ocorre recorrentemente por meio de práticas que desconfiguram o CT como órgão autônomo de função político-administrativa. Os psicólogos inseridos no CT não devem, assim, se ocupar de serviços periciais e socioassistenciais ausentes ou precários no município, mas exercer funções que vão subsidiar as ações executadas pelos conselheiros tutelares. São apresentadas três possíveis atribuições nesses contextos: 1) capacitação e formação continuada a conselheiros tutelares; 2) supervisão técnica à delegação de medidas protetivas e encaminhamentos jurídicos; e 3) apoio técnico às atividades de caráter preventivo, de fiscalização e de cobrança. Sugere-se que a implementação de equipes multidisciplinares destinadas a assessorar o CT em suas funções deva ser regulamentada em nível federal.

Palavras-chave: políticas públicas; atuação do psicólogo; direitos da criança; conselho tutelar.
\end{abstract}

\section{THE ROLE OF PSYCHOLOGISTS AT CHILD PROTECTION AGENCIES}

\begin{abstract}
This theoretical study aims to suggest guidelines for the role of psychologists at child protection agencies (CPAs). It was motivated by the comprehension that the inclusion of psychology at CPAs currently occurs through practices that unset CPAs as autonomous bodies with its political and administrative role. Psychologists inserted at CPAs should not engage at forensic and social assistance services that are absent and precarious in the community, but instead they should perform tasks that will support the actions taken by CPAs. It is presented three possible assignments concerning these contexts: 1) training and continuing education to CPAs' workers; 2) technical supervision to the delegation of protective measures and legal referrals; and 3 ) technical support to preventive, monitoring, and demanding activities. It is suggested that the implementation of multidisciplinary teams designed to assist the CPAs' functions should be regulated at federal level.
\end{abstract}

Keywords: public policies; psychologist role; children rights; child protection agency. 


\section{LA ACTUACIÓN DE PSICÓLOGOS EN CONSEJOS TUTELARES}

\section{Resumen}

Este estudio teórico sugiere directrices para la práctica de psicólogos en el Consejo Tutelar (CT). El escrito está motivado por el entendimiento de que la inclusión de la psicología en el CT se produce recurrentemente por medio de prácticas que desconfiguran el CT como órgano autónomo de función político-administrativa. Los psicólogos no deben ocuparse con servicios periciales y de asistencia social ausentes o precarios en el municipio, sino realizar las tareas que apoyarán las acciones tomadas por los consejeros tutelares. Se presenta tres posibles orientaciones: 1) formación y educación continua a los consejeros tutelares; 2) supervisiones técnicas para la delegación de las medidas de protección y derivaciones legales; y 3) apoyo técnico a las actividades de prevención, monitoreo y recolección. Se sugiere que la implementación de equipos multidisciplinarios destinados a ayudar al CT debe ser regulada a nivel federal.

Palabras clave: políticas públicas; actuación del psicólogo; derechos de los niños; consejo tutelar.

\section{INTRODUÇÃO}

O objetivo do presente artigo é sugerir diretrizes para a atuação de psicólogos no Conselho Tutelar (CT). Sua motivação deu-se a partir da verificação de que a literatura científica carece de trabalhos que discutam a relação entre psicologia e CT. A partir de buscas em diferentes bases de dados (SciELO, LILACS, PePSIC e Index Psi) encontrou-se apenas um relato de experiência (Sequeira, Monti, \& Braconnot, 2010) que refletia sobre aspectos relacionados à prática psicológica nesses espaços. Ainda que os autores tenham trazido importantes considerações sobre a inserção técnica em tais contextos, observou-se a descrição de ações socioassistenciais que desconfiguram o CT como órgão administrativo autônomo.

A imprecisão quanto ao papel do psicólogo no CT pode se relacionar com a história da inserção técnica em instituições de políticas públicas no Brasil. Há relatos assistemáticos e pontuais sobre a atuação de psicólogos em diversos setores públicos desde meados do século passado. Todavia, foi somente com os movimentos democráticos da década de 1980 que essas alocações se tornaram oficiais em todo o país, a partir das promulgações de leis embasadas nos princípios da Constituição Federativa da República do Brasil, de 1988 (Yamamoto \& Oliveira, 2010). Dentre essas leis, destacam-se: o Estatuto de Criança e do Adolescente (ECA; Presidência da República, 1990), que regulamentou a inserção de equipes interprofissionais (as quais incluem psicólogos) nos Juizados da Infância e da Juventude; a Portaria n. 154, de 14 de Janeiro de 2008, do Ministério da Saúde (2008), que regulamentou a inserção de psicólogos nos Núcleos de Atenção à Saúde da Família; e a Lei Federal n. 12.435, de 6 de Julho de 2011 (Presidência da República, 2011), que regulamentou a inserção de equipes de referências (as quais incluem psicólogos) no Sistema Único da Assistência Social. Não há, contudo, leis federais que regulamentem a inserção de equipes técnicas em CTs. Ainda que o regimento de cada CT seja instituído 
por leis municipais, diretrizes federais poderiam estabelecer a formação de tais equipes, delimitando suas funções nesse contexto.

A ausência de diretrizes ou produções científicas que se dediquem a nortear a atuação do psicólogo em CTs contribui para que tais inserções técnicas ocorram como substitutivas aos serviços precários ou ausentes no município. Essas práticas, além de irregulares perante a lei, retroalimentam o contexto de privação de direitos de crianças e dos adolescentes, tendo em vista que eximem os CTs de sua função de prevenção, fiscalização e cobrança. Essa realocação das atribuições técnicas exime também os órgãos judiciais de suas funções juridiscionais e os órgãos de atendimento de suas funções socioassistenciais, uma vez que se pode observar psicólogos efetuando perícias e atendimentos psicoterapêuticos em CTs. A efetuação de tais modalidades de atendimento no CT pode ser consequência da tendência observada em psicólogos inseridos em instituições de políticas públicas em promover, sobretudo, atendimentos individuais à população. Tal tendência vai na contramão dos princípios previstos pelas leis que fundam esses cargos públicos, segundo os quais os psicólogos devem exercer sobretudo ações de caráter coletivo (Yamamoto \& Oliveira, 2010).

A atuação de psicólogos em CTs pode ocorrer com irregularidades se não compreendidas as diferenças entre órgãos judiciais, legislativos e administrativos. Os órgãos judiciais são aqueles ligados ao Poder Judiciário e possuem, portanto, função jurisdicional, isto é, julgam conflitos de interesse por meio do processo. Os órgãos legislativos estão ligados ao Poder Legislativo e têm a função de legislar, ou seja, criar leis e fiscalizar o Poder Executivo. Os órgãos administrativos estão vinculados ao Poder Executivo e têm a função de executar função pública administrativa, bem como elaborar políticas que forneçam diretrizes para a administração pública (Alexandrino \& Paulo, 2013). Com base neste entendimento, os CTs devem ser compreendidos como órgãos administrativos, que têm a função de zelar pelo cumprimento dos direitos das crianças e dos adolescentes, acionando órgãos judiciais quando dos casos de ameaça ou violação desses direitos. Isto significa dizer que, como órgão administrativo, não é função do CT apreciar conflitos de interesse, função esta desempenhada pelos Juizados Especiais - no caso de demandas oriundas no CT, sobretudo, o Juizado da Infância e Juventude e o Juizado da Família - e pelo Ministério Público.

Como órgão administrativo, o CT deve ser compreendido ainda como órgão autônomo, isto é, um órgão diretivo com ampla autonomia administrativa (Alexandrino \& Paulo, 2013). Sua função como órgão autônomo é política, e não técnica, sendo a prestação de serviços à população função dos órgãos de atendimento (Kaminski, 2002), tais como as unidades de saúde da família ou os centros de referência em assistência social. A prestação de serviços socioassistenciais por parte do CT significa que o órgão assumiu as atribuições de 
outros estabelecimentos, compactuando com as irregularidades presentes no município e deixando de cumprir sua função fiscalizadora. Nessa perspectiva, os CTs acionam outros órgãos administrativos quando da necessidade de atendimento da população em serviços nas áreas de saúde, educação, serviço social, previdência, trabalho e segurança (Presidência da República, 1990, Art. n. 136, III)

A atuação do psicólogo em CT implica, pois, questões cruciais, que são permeadas por aspectos não apenas técnicos e éticos, mas também legais: Qual o papel do saber técnico em um órgão administrativo autônomo, como o CT? Quais as possíveis atribuições de psicólogos em tais espaços?

O presente trabalho configura-se como um ensaio teórico, com base em estudo não sistemático da legislação nacional (em especial o ECA) e em trabalhos científicos que tenham o CT como foco de análise. Seu objetivo geral, como supracitado, é sugerir diretrizes para a atuação do psicólogo no CT. A fim de atingir tal objetivo, inicialmente, situou-se a origem do CT na legislação brasileira, destacando-se suas atribuições como órgão de garantia de direitos. Em seguida, debateu-se sobre a consistência da atuação técnica junto aos CTs como forma de fornecer apoio às ações desenvolvidas pelos conselheiros tutelares. Por último, sugeriram-se possíveis atribuições dos psicólogos inseridos em tais modelos de equipes técnicas, destacando a importância desse saber técnico no subsídio às ações dos conselheiros tutelares. As diretrizes aqui propostas respeitam a delimitação do CT como órgão administrativo autônomo, evitando a perpetuação de práticas psicológicas socioassistenciais e periciais que desconfiguram sua função político-administrativa.

\section{CONSELHO TUTELAR: ORIGEM, DEFINIÇÃO E ATRIBUIÇÕES}

As primeiras legislações específicas sobre infância e adolescência datam, na Europa, do início da década de 20 do século passado, o que influenciou, no Brasil, a promulgação do Código de Menores, em 1927, editado posteriormente em 1979. Em seu artigo 20, o Código de Menores (Presidência da República, 1979) reconhecia como "em situação irregular" crianças e adolescentes vítimas de negligência, maus tratos e violência por ação, omissão, impossibilidade ou falta do exercício parental, bem como autores de ato infracional e/ou "com desvio de conduta". Ainda que trouxesse inovações acerca dos direitos de tais sujeitos, a lei legitimava práticas higienistas que se preocupavam muito mais com a limpeza da cidade que com o bem-estar de seus atendidos (Rizzini \& Pilotti, 2011).

Com a promulgação da Constituição Federativa da República do Brasil, de 1988, e o ECA, em 1990, a Doutrina da Situação Irregular é então substituída pela Doutrina da Proteção Integral. A Doutrina da Situação Regular era a base jurídica do Código de Menores, caracterizada majoritariamente por pressupostos 
e implicações de forte caráter higienista. A Doutrina da Proteção Integral, todavia, trouxe uma visão garantista de direitos, de modo a conceber crianças e adolescentes como seres de direitos e deveres e em situação peculiar do desenvolvimento. Com ela, tornou-se constitucional, por meio do artigo 227, a prioridade absoluta aos direitos das crianças e adolescentes:

"É dever da família, da sociedade e do Estado assegurar à criança e ao adolescente, com absoluta prioridade, o direito à vida, à saúde, à alimentação, à educação, ao lazer, à profissionalização, à cultura, à dignidade, ao respeito, à liberdade e à convivência familiar e comunitária, além de colocá-los a salvo de toda forma de negligência, discriminação, exploração, violência, crueldade e opressão." (Presidência da República, 1988, Art. n. 227)

De acordo com este novo paradigma jurídico, quando em privação de seus direitos fundamentais, não é a criança ou o adolescente quem está em situação irregular, mas sua família, a sociedade e/ou o Estado.

A promulgação do ECA significou ainda um conjunto de mudanças na institucionalização do serviço ofertado às crianças e adolescentes brasileiros (Xaud, 2000). No artigo 70 do Código de Menores (Presidência da República, 1979) constava que "À autoridade judiciária competirá exercer diretamente, ou por intermédio de servidor efetivo ou de voluntário credenciado, fiscalização sobre o cumprimento das decisões judiciais ou determinações administrativas que houver tomado com relação à assistência, proteção e vigilância a menores", de modo que para a figura do Juiz de Menores convergiam funções jurisdicionais e administrativas. É somente com o advento do ECA (Presidência da República, 1990) que estas funções passaram a ser divididas entre o Juizado da Infância e Juventude e a sociedade civil, representada pelo CT. Enquanto ao primeiro coube a execução de funções jurisdicionais, ao segundo dirigiu-se funções políticoadministrativas referentes à vigilância e garantia dos direitos de crianças e adolescentes.

Segundo o ECA (Presidência da República, 1990, Art. n. 131), "O Conselho Tutelar é órgão permanente e autônomo, não jurisdicional, encarregado pela sociedade de zelar pelo cumprimento dos direitos da criança e do adolescente". Isso significa dizer que o CT é uma unidade organizacional coletiva, eleita pela população local e representante dela diante do Estado no que concerne à garantia dos direitos das crianças e dos adolescentes. Significa ainda que seus membros, quando apossados de seus cargos, podem deliberar e agir, de maneira contínua e ininterrupta, segundo as funções que lhe são atribuídas pelo ECA. Ademais, ao executar suas funções, não lhes cabe apreciar ou julgar conflitos de interesse, mas fiscalizar o cumprimento dos direitos infanto-juvenis previstos em legislação (Bulhões, 2010; Gebeluka \& Bourguignon, 2010).

Dentre as atribuições dos conselheiros tutelares (Presidência da República, 1990, Art. n. 136), destaca-se a delegação de medidas protetivas a crianças e 
adolescentes que tenham seus direitos ameaçados ou violados, bem como a crianças de até 12 anos incompletos autoras de ato infracional (Inciso I). Cabe ao CT também providenciar as medidas protetivas determinadas pelas autoridades judiciais a adolescentes e jovens de 12 a 21 anos incompletos autores de ato infracional (Inciso VI). As medidas protetivas mencionadas estão descritas nos sete primeiros incisos do artigo 101 do ECA e referem-se a encaminhamento aos pais (Inciso I), orientação, apoio e acompanhamento temporários (Inciso II) e acesso a outros serviços e programas como forma de garantia de seus direitos (Inciso III ao VII).

É previsto o atendimento e aconselhamento a pais e responsáveis (Presidência da República, 1990, Art. n. 136, II), aplicando-lhes as medidas protetivas previstas nos sete primeiros incisos do artigo 129 do ECA. Essas medidas protetivas são: acesso a outros serviços como forma de garantia de direitos (Incisos I a IV); obrigação de matricular o filho em escola (Inciso V) e encaminhá-lo a atendimento especializado (Inciso VI); e advertência (Inciso VII). O Art. 18-B declara sobre medidas aplicadas a pessoas que utilizarem métodos educativos coercitivos no tratamento de crianças e adolescentes. Estas medidas incluem acesso a outros serviços (Incisos I a II), frequência em curso ou programa de orientação (Inciso III), obrigação de encaminhar criança ou adolescente a atendimento especializado (Inciso IV) e advertência (Inciso V).

A fim de promover essas medidas protetivas, seja às crianças e adolescentes ou a seus pais e responsáveis, o CT pode realizar encaminhamentos a órgãos de atendimento, podendo representar ao Ministério Público os casos em que suas deliberações foram descumpridas sem justificativa (Presidência da República, 1990, Art. 136, III). É por meio do trabalho em rede que as famílias acessam seus direitos, o que reforça a necessidade de que haja uma comunicação e articulação institucional efetiva (Deslandes \& Campos, 2015).

São atribuições dos conselheiros tutelares ainda o encaminhamento de casos específicos a órgãos jurídicos. Ao Ministério Público, os casos em que se verifiquem crime ou infração administrativa contra os direitos das crianças ou adolescentes (Presidência da República, 1990, Art. n. 136, Inciso IV), como, por exemplo, situações em que se verifique a prática de violência doméstica, sexual, etc. contra crianças e adolescentes. Às autoridades judiciárias, os casos de competência jurisdicional (Presidência da República, 1990, Art. n. 136, Inciso V), como, por exemplo, situações de litígio, guarda, tutela, adoção, cometimento de ato infracional, entre outras que apresentem repercusões nos direitos de crianças e adolescentes. Cabe também ao CT expedir notificações (Presidência da República, 1990, Art. n. 136, Inciso VII) e representar ao Ministério Público ações de perda ou suspensão do poder familiar, após esgotadas demais tentativas de manter a criança ou o adolescente com o convívio de sua família (Presidência da República, 1990, Art. n. 136, Inciso XI). 
Kaminski (2002) aludiu que o CT, como órgão administrativo, não deve funcionar de modo a oferecer serviços substitutos àqueles precários ou ausentes no município. Em tais casos, o CT perpetuaria a omissão dos direitos que protege ao eximir o Poder Executivo local de suas funções. O autor acrescentou que o CT encontra sua excelência em atividades no âmbito da prevenção, da fiscalização e da posterior cobrança do Estado por políticas públicas de qualidade. Dessa forma, o CT combate os problemas sociais, econômicos e políticos advindos da contradição capital-trabalho - definida por Netto (2007) como "questão social". Nessa perspectiva, o CT deve ser compreendido como um órgão de atuação comunitária que deve promover a cidadania e o desenvolvimento local (Frizzo \& Sarriera, 2005).

As ações de caráter preventivo parecem coincidir com aquela expressa no inciso XII do artigo 136 do ECA (Presidência da República, 1990): a de "promover e incentivar, na comunidade e nos grupos profissionais, ações de divulgação e treinamento para o reconhecimento de sintomas de maus-tratos em crianças e adolescentes". As atribuições de fiscalização relacionam-se com aquelas previstas pelo ECA nos artigos 95, 191 e 194: a de fiscalizar profissionais e entidades de atendimento a crianças e adolescentes. As ações de cobrança referem-se àquelas descrita no inciso IX do artigo 136: assessorar o Poder Executivo local no que diz respeito à elaboração da proposta orçamentária concernente ao atendimento de crianças e adolescentes. Na execução desta função, destaca-se o diálogo existente entre CT e Conselho Municial de Direitos da Criança e do Adolescente (CMDCA), que pressionam o Poder Executivo local conjuntamente em prol da execução de políticas públicas conforme as necessidades da população. CT e CMDCA devem, assim, atuar não apenas na elaboração dessas políticas públicas, mas também no acompanhamento da execução do orçamento aprovado (Batista \& Cerqueira-Santos, 2012).

No artigo 136 do ECA (Presidência da República, 1990) há outras atribuições que não serão discutidas neste trabalho, por não se articular com o objetivo proposto: requisitar certidãos de nascimento ou de óbito de crianças e adolescentes (Inciso VIII); e representar em caso de programação televisiva ou de rádio que viole os direitos da criança e do adolescente (Inciso $\mathrm{X}$ ).

\section{CONSELHO TUTELAR E SABER TÉCNICO}

A atuação do CT envolve contextos complexos, sendo fadadas ao fracasso concepções fragmentadas da realidade a ser estudada. Os conselheiros tutelares, além de munidos de conhecimento político, devem dispor de competências que permitam um olhar multifacetado sob as demandas que adentram ao CT, a fim de planejar e coordenar com maior precisão as ações a serem implementadas pelo órgão. Dessa forma, poderão garantir a execução das medidas protetivas e encaminhamentos jurídicos previstos por lei (Desaulniers, 2002). 
Kaminski (2002) apontou que o projeto de lei que dispôs sobre a criação do CT previa que, da composição dos membros do órgão, três deveriam ser de formação universitária em áreas específicas (direito, educação, saúde, psicologia e serviço social) e os outros dois escolhidos mediante indicação de entidades de defesa e de atendimento de direitos. O autor declarou que tais requisitos se fundamentavam na concepção de CT como órgão de atendimento, de modo que, tão logo inaugurada sua concepção como órgão administrativo autônomo, o saber técnico tornou-se secundário, mantendo-se apenas os requisitos gerais de candidatura já presentes no projeto de lei. Esses requisitos são: "I - reconhecida idoneidade moral; II - idade superior a vinte e um anos; III - residir no município" (Presidência da República, 1990, Art. n. 133), cabendo ao Município estabelecer sobre outros critérios que julgarem pertinentes conforme a realidade local.

A retirada de requisitos técnicos para a candidatura como conselheiro tutelar não significa, entretanto, que não se possa haver equipes técnicas que subsidiem as decisões tomadas pelos conselheiros. A argumentação reativa à inserção de equipes técnicas no CT pode seguir na direção de que a realização de perícias e a prestação de serviços socioassistenciais e terapêuticos no local perpetuaria as irregularidades no atendimento às crianças e adolescentes no município, uma vez que o CT executaria a função das entidades judiciais e de atendimento. Esta concepção é de fato coerente se os profissionais técnicos se ocuparem com serviços substutivos àqueles ausentes ou precários no município, mas suas atribuições não são estas. Ao se inserir em um órgão autônomo de função política, os psicólogos devem aprimorar e otimizar os serviços oferecidos pelo órgão, promovendo o direito de crianças e adolescentes por meio de um olhar especializado que subsidie as decisões a serem tomadas pelos conselheiros tutelares.

Algumas leis municipais regulamentam o apoio técnico interdisciplinar para o subsídio das práticas realizadas nos CTs. Destaca-se a experiência do Rio de Janeiro, tendo-se regulamentado por lei que: "A Secretaria Municipal de Desenvolvimento Social, mediante seu órgão competente, prestará o apoio técnico interdisciplinar indispensável ao regular exercício das funções dos Conselhos" (Câmara Municipal do Rio de Janeiro, 2001, Art. n. 20, parágrafo único).

Dentre os poucos trabalhos que discutem tais inserções, destaca-se uma experiência relatada em São Paulo (Sequeira et al., 2010), em que estagiários de psicologia realizaram atividades de grupo com adolescentes atendidos no CT por problemas de comportamento. Esta função parece esbarrar nas atribuições dos órgãos de atendimento socioassistenciais, de modo que o CT estaria oferecendo serviços precários ou ausentes no município. Por tal razão, parece impertinente a inserção de psicólogos em serviços nesse formato. Ainda assim, julga-se pertinente a conclusão a que chegaram as autoras: "A Psicologia pode e deve se 
inserir nessa instituição [o CT], de forma a contribuir para a promoção de saúde da população, buscando a garantia do desenvolvimento pleno da criança e do adolescente" (p. 865). O que se defende aqui, no entanto, é que essa promoção de direitos deve se dar para além da prestação de serviços precários ou ausentes no município. Em casos como esses, o corpo técnico perpetua as irregularidades do município na prestação de serviços a crianças e adolescentes.

\section{POSSÍVEIS ATRIBUIÇõES DO PSICÓLOGO NO CONSELHO TUTELAR}

Os psicólogos trabalhando em CTs devem ocupar uma função diferente daquela desempenhada pelos conselheiros tutelares. Enquanto os últimos tornam-se responsáveis pelo atendimento à população local e delegação de medidas protetivas, aqueles têm como responsabilidade o exercício de funções como forma de subsidiar e otimizar as ações promovidas pelo órgão. Nesse sentido, os psicólogos deveriam compor equipes técnicas que teriam como função o apoio aos conselheiros tutelares e, não, o atendimento à população.

A atuação dos psicólogos deve funcionar no sentido de desvelar as demandas técnicas que são solicitadas à psicologia no campo jurídico, com o devido olhar atento que evita a reprodução da violência estrutural presente na sociedade contemporânea. Isso significa que, ao atender as demandas de ordem jurídica, os psicólogos devem ter um olhar crítico, atentando-se para que, por meio de seu discurso, não sejam alastradas verdades que estigmatizem seus atendidos, mas um olhar de complexidade sobre sua existência e realidade social (Arantes, 2011).

A atuação dos psicólogos em CTs deve ter como base ações de promoção à saúde, desenvolvendo a autonomia e potencialidades da população. Nessa perspectiva, os atendidos pelo órgão adotam a postura de sujeitos propriamente ditos, tornando-se mais críticos (Sequeira et al., 2010). Ademais, sua atuação deve ser instrumentalizada pelo ECA, munindo-se da concepção de infância e adolescência apresentada pela lei, qual seja: a de sujeitos de direitos e responsabilidade em situação peculiar do desenvolvimento (Brambilla \& Avoglia, 2010).

Devido à complexidade que envolve as ações do $\mathrm{CT}$, múltiplas demandas de atendimento podem emergir para os psicólogos, sempre no sentido de subsidiar as ações dos conselheiros tutelares. O presente trabalho apresenta três possíveis atribuições a psicólogos que se insiram em tais equipes técnicas de apoio.

\section{Capacitação e Formação Continuada a Conselheiros Tutelares}

Conforme já assinalado, não há requisitos técnicos para a nomeação de uma pessoa como conselheiro tutelar. Isso não significa, contudo, negar as contribuições que podem advir da participação de profissionais com formação 
técnica em CTs. Tais profissionais podem contribuir significativamente para a construção coletiva de conhecimentos importantes para atuação frente a esse campo marcado pela complexidade. Nesse sentido, os psicólogos podem colaborar em processos de capacitação e formação continuada de conselheiros tutelares, possibilitando trocas permanentes sobre diversas questões que compõem o cotidiano de trabalho desse órgão. Esses processos de capacitação poderão produzir reflexos nas ações e tomadas de posições posteriores.

Os resultados do estudo de Frizzo e Sarriera (2006) salientam a visão por parte de outros profissionais da rede de apoio à infância e adolescência acerca do trabalho do conselheiro tutelar, que pode ser resumida em uma palavra: despreparo. Tais resultados endossam a ideia de que a construção coletiva de um projeto de formação permanente pode ser de grande utilidade, propiciando a produção de espaços de trocas em que ambos os saberes (popular e técnico/científico) sejam valorizados e estejam dispostos horizontalmente. Esses espaços podem ser traduzidos em encontros formais (reuniões semanais ou quinzenais, organização de fóruns e de seminários internos, produção de cartilhas) e/ou informais (conversas informais, entre outras), e devem ser orientados pelos "valores éticos de respeito, solidariedade e compromisso" (Sarriera, 2010, p. 28), conforme se prevê para atuação do psicólogo com populações em situação de vulnerabilidade. Acredita-se que a potencialidade desses espaços coletivos de formação continuada é enorme, permitindo a construção conjunta de programas para tratar das mais diversas questões relacionadas ao campo de atuação dos conselheiros tutelares - tais como: papel do $\mathrm{CT}$, direitos da criança e do adolescente, questões sobre desenvolvimento humano, entre outras - além de possibilitar o diálogo sobre a promoção de estratégias de mobilização social e participação popular.

Motti (2012) propõe que no campo das políticas públicas, "formar continuamente deve ser uma meta" (p. 190). O referido autor discute uma proposta de formação continuada para conselheiros tutelares e reconhece que tal formação não dá conta de todas as questões envolvidas no processo. Ressalta, assim, a importância da formação como "instrumento para promover a transformação da consciência, da forma de ver e, por consequência, de pensar e agir" (p. 194).

Supervisões Técnicas para Delegação de Medidas Protetivas e Encaminhamentos Jurídicos

As ações direcionadas aos núcleos familiares em atendimento no CT referem-se, sobretudo, à delegação de medidas protetivas e a encaminhamentos jurídicos, a depender da situação de ameaça ou violação de direitos de crianças e adolescentes. Essas ações podem ser otimizadas a partir de um olhar técnico especializado, evitando-se interpretações embasadas somente pelo senso comum. Nesse sentido, os conselheiros tutelares poderiam recorrer a psicólogos 
nas situações em que o conhecimento psicológico pode lançar luz sobre os casos em atendimento, otimizando as ações promovidas pelo órgão a partir de supervisões de cunho técnico-psicológico. Abaixo serão discutidas algumas possíveis situações em que essas supervisões técnicas poderiam ocorrer.

O ECA (Presidência da República, 1990, Art. n. 56) delimita que ao CT devem ser comunicados, pelos dirigentes de estabelecimento de ensino fundamental, os casos de crianças e adolescentes com faltas escolares recorrentes e/ou elevados índices de repetência. Nessas ocasiões, um olhar técnico especializado pode elucidar o fenômeno em questão, de modo a auxiliar na identificação de possíveis fatores de risco associados - dificuldades de aprendizagem, alteração neuropsicológica, conflitos familiares, consumo de psicotrópicos, envolvimento em atos infracionais, etc. Essa articulação entre CT e escola deve se dar, sobretudo, a partir de uma lógica garantista e, não, como um fazer moralista (Fernandes \& Aragão, 2011) ou que penaliza os alunos encaminhados (Scheinvar, 2012).

Supervisões técnicas promovidas por psicólogos aos conselheiros tutelares podem, assim, otimizar a delegação de medidas protetivas conforme a peculiaridade dos casos encaminhados pela escola. Nos casos de dificuldades de aprendizagem e alterações neuropsicológicas, requisições de tratamento médico, psicológico e/ou psiquiátrico (Presidência da República, 1990, Art. n. 101, V) são convenientes. Em situações específicas, em que verificadas deficiências físicas e/ou intectuais, o CT deve solicitar atendimento educacional especializado (Presidência da República, 1990, Art. n. 54, III), de modo que as supervisões técnicas promovidas por psicólogos podem subsidiar tais solicitações. Nas situações de conflitos familiares, consumo de psicotrópicos e envolvimento em atos infracionais, os conselheiros tutelares podem sugerir a inserção em serviços e programas de proteção, apoio e promoção à família, crianças e adolescentes (Presidência da República, 1990, Art. n. 101, IV) e/ou em programas de orientação e tratamento de toxicômanos (Presidência da República, 1990, Art. n. 101, VI).

Ainda no âmbito das demandas escolares, supervisões técnicas promovidas por psicólogos aos conselheiros tutelares poderiam apoiar suas tomadas de decisões. Nesse sentido, um olhar especializado pode auxiliar a compreensão de possíveis práticas de bullying e demais situações de violência, delegando-se medidas protetivas conforme a necessidade de cada caso - em geral a tratamento psicológico (Presidência da República, 1990, Art. n. 101, V) e inserção em serviços e programas de proteção, apoio e promoção à família, crianças e adolescentes (Presidência da República, 1990, Art. n. 101, IV). O CT pode sugerir a mudança dos alunos de turma ou escola como forma de garantir seus direitos (Souza, Teixeira, \& Silva, 2003), de modo que as supervisões técnicas promovidas por psicólogos poderiam subsidiar tais sugestões. Nesses casos, a escola também deve ser comunicada, exigindo-se providências cabíveis 
para a resolução dessas situações de violência. Psicólogos inseridos nos CTs poderiam trabalhar conjuntamente com os conselheiros tutelares no sentido de estabelecer estratégias de intervenções que visem à conscientização e mobilização da escola para a redução de tais ocorrências (Presidência da República, 1990, Art. n. 136, XII).

Elevado índice de pais busca o CT por orientação com relação aos filhos, frequentemente inseridos em contextos de evasão escolar, práticas de atos infracionais e consumo de substâncias psicotrópicas (Sequeira et al., 2010). Como já citado, esse tipo de demanda pode advir também de encaminhamentos de dirigentes de estabelecimentos de ensino (Presidência da República, 1990, Art. n. 56, II). Os responsáveis, em tais situações, comumente se eximem da implicação direta de sua postura com a conduta dos adolescentes, atribuindo a responsabilidade pelos problemas apresentados às "más companhias" com quem convivem (Sequeira et al., 2010). Pedidos de internações, agressões físicas e outros procedimentos coercitivos são recorrentemente defendidos pelos responsáveis como formas eficazes de lidar com o problema (Espíndula, Trindade, \& Santos, 2009).

Os casos em que as ações do CT forem insuficientes para a solução do problema são encaminhados às autoridades judiciárias, que abrem um processo de providência. Essas situações assemelham-se muito aos casos de crianças e adolescentes autores de atos infracionais, ainda que, nos últimos casos, complexidade peculiar é observada, uma vez já verificada a prática de ato infracional. No caso de crianças autoras de ato infracional, é o próprio CT quem delega as medidas protetivas. No caso de adolescentes, a delegação das medidas protetivas e socioeducativas é feita pelas autoridades judiciais e não pelo CT. Ainda que previsto por lei, o CT não tem sido notificado quanto à prática de ato infracional por adolescentes de sua região (Bazon, 2008), o que denuncia a problemática comunicação entre $\mathrm{CT}$, Ministério Público, Justiça e Poder Executivo, na complexa rede de atendimento a adolescentes em conflito com a lei.

O atendimento a crianças e adolescentes (potencialmente) autores de atos infracionais deve buscar "estabelecer uma relação de proximidade, escuta e acolhimento" (Sequeira et al., 2010, p. 864), evitando postura penalista e verificando os fatores que se relacionam com a eclosão de tais condutas. Supervisões técnicas promovidas por psicólogos aos conselheiros tutelares poderiam contribuir para o entendimento dos casos, de modo a destacar os fatores de risco e proteção associados. Dentre os fatores de risco, destacam-se: relações familiares conflituosas; negligência; exposição à violência; dificuldades de aprendizagem; privação de recursos e atividades de lazer; relações com pares vinculados com atividades infracionais; etc. Os fatores de proteção, por sua vez, envolvem: autoestima; interesses em esportes, artes, etc.; relações positivas 
estabelecidas com professores e outros adultos; acesso a atividades de lazer; etc.

A partir da análise de fatores de risco e proteção, os conselheiros tutelares têm maiores subsídios para promover a orientação, apoio e acompanhamentos temporários (Presidência da República, 1990, Art. 101, II), bem como delegar medidas protetivas a fim de que a criança/adolescente e sua família acessem a rede e garantam seus direitos. Essas medidas envolvem, como já mencionado, requisições de tratamento médico, psicológico e/ou psiquiátrico (Presidência da República, 1990, Art. n. 101, V), inserção em serviços e programas de proteção, apoio e promoção à família, crianças e adolescentes (Presidência da República, 1990, Art. n. 101, IV) e/ou em programas de orientação e tratamento de toxicômanos (Presidência da República, 1990, Art. n. 101, VI). Nos casos de evação escolar, pode-se requisitar a matrícula em estabelecimento de ensino (Presidência da República, 1990, Art. n. 101, III). Os pais e responsáveis podem também ser alvo de medidas, que envolvem a inclusão em tratamentos, cursos e serviços; e a obrigação em acompanhar o filho nas medidas protetivas delegadas (Presidência da República, 1990, Art. n. 129).

A demanda mais conhecida, em se tratando de CT, são os casos de maustratos envolvendo crianças e adolescentes, seja violência física, psicológica, sexual ou negligência. No ECA (Presidência da República, 1990, Art. n. 13, Art. n. 56 \& Art. n. 70-B) fica ressaltada a necessidade de comunicação destes casos ao $\mathrm{CT}$, que é responsável por suas notificações e medidas protetivas pertinentes. Nessas situações, não cabe ao psicólogo práticas periciais, funções estas desempenhadas pelas equipes técnicas dos Juizados da Infância e Juventude. Assim como nos casos de conflito com a lei e providência, supervisões técnicas promovidas por psicólogos podem auxiliar na identificação dos fatores de risco e de proteção, de modo a otimizar as medidas protetivas delegadas pelos conselheiros tutelares. Essas medidas envolvem a requisição a tratamento médico e psicológico (Art. 101., IV) e a inserção em serviços e programas de proteção, apoio e promoção à família, crianças e adolescentes (Art. n. 101, IV). Os pais e responsáveis podem também ser alvo de medidas (Art. n. 129). Nos casos mais graves, pode ser solicitado o acolhimento institucional de crianças e adolescentes (Art. 101, VII) e a perda ou suspensão do poder familiar (Art. 136, XII). Os casos de suspeita de ameaça ou violação de direitos devem ser representados ao MP (Art. n. 136, IV) e aos supostos agressores devem ser aplicadas medidas previstas por lei (Art. n. 18-B), dentre elas a obrigação à frequência a cursos ou programas de orientação (Inciso III). Esses cursos podem ser planejados pelos psicólogos inseridos no CT.

Os psicólogos inseridos em CTs podem, portanto, engajar em supervisões técnicas promovidas aos conselheiros tutelares como forma de subsidiar as ações a serem tomadas. Nos parágrafos acima, foram apresentadas algumas situações em que o conhecimento psicológico poderia elucidar os atendimentos, mas 
outros exemplos poderiam ser descritos, tendo em vista a pluralidade de demandas que chegam aos CTs. As supervisões técnicas sugeridas como atribuições de psicólogos devem ser requeridas pelos conselheiros tutelares ao se depararem com casos cuja complexidade necessita um olhar especializado. Esses encontros entre psicólogos e conselheiros tutelares devem ocorrer de forma que os conselheiros tutelares expressem suas percepções sobre os casos, solicitando um olhar técnico que possibilite melhor subsidiar as ações futuras. Os psicólogos devem assumir uma postura de escuta e analisar o conteúdo trazido pelos conselheiros com base em teorias psicológicas. Munidos desse olhar especializado, são os conselheiros tutelares que decidem sobre as delegações de medidas protetivas e encaminhamentos jurídicos cabíveis.

Para além dos encontros entre psicólogos e conselheiros tutelares, essas supervisões técnicas podem se dar também a partir de encontros entre psicólogos e os núcleos familiares em atendimento no CT. Tais ações devem ocorrer, contudo, somente de forma pontual, tendo em vista o caráter do CT de fomentar na sociedade civil a postura de reivindicação de direitos. Os conselheiros tutelares, nesse sentido, tornam-se representantes locais desse objetivo constitucional, de modo que o saber técnico não deve se sobrepor ao fazer popular. Os encontros entre psicólogos e núcleos familiares em atendimento não devem possuir finalidade socioassistencial, tampouco pericial. A finalidade dos encontros é possibilitar ao psicólogo o contato com os casos de maior complexidade, segundo sugestão dos próprios conselheiros. A partir do contato direto com esses casos, o psicólogo pode contribuir com subsídios para as ações a serem tomadas pelos conselheiros. Esta deve ser, sobretudo, a função dos psicólogos nos CTs: subsisiar as ações dos conselheiros tutelares.

Apoio Técnico às Atividades de Caráter Preventivo, de Fiscalização e de Cobrança

Ainda que o atendimento às demandas supradescritas tenha imensurável relevância, em se tratando de medidas protetivas e encaminhamentos jurídicos que visam a garantir direitos de crianças e adolescentes, restringe-se ao âmbito individual. Contribuem, pois, muito pouco para a atenuação dos problemas sociais, econômicos e políticos gerados pela "questão social" (Netto, 2007). Os psicólogos podem apoiar os conselheiros tutelares também em suas ações de caráter preventivo, de fiscalização e de cobrança, provendo conhecimento técnico que otimize seu planejamento, sua execução e a análise de seus resultados. A seguir serão descritas algumas dessas situações nas quais os psicólogos podem trazer apoio técnico.

Campanhas de caráter educacional podem e devem ser realizadas pelo CT como forma de auxiliar na prevenção das violações de direitos das crianças e dos adolescentes (Presidência da República, 1990, Art. n. 136, XII). Os psicólogos, nesse sentido, podem contribuir diretamente na construção de estratégias de conscientização e mobilização local. Os psicólogos podem também participar 
diretamente na execução dessas campanhas, oferecendo, por exemplo, palestras expositivas e dialogadas sobre diferentes temas, definidos com a participação da população, sobre os quais a psicologia poderia contribuir de maneira efetiva (consumo de drogas, violência, aprendizagem, desenvolvimento humano etc.). Outros métodos também podem ser utilizados, tais como dinâmicas de grupos, levantamentos etc. Por último, os psicólogos podem trazer contribuições no sentido de avaliar os resultados posteriores das campanhas na população, desenvolvendo, para tanto, diferentes métodos, de perspectiva qualitativa (entrevistas, observações, grupos focais, conversas informais etc.) e quantitativa (questionários fechados).

No que se refere às atividades de fiscalização, o CT pode e deve desenvolver visitas institucionais a programas de atendimento socioeducativos, casas de acolhimento institucional e demais entidades de atendimento a crianças e adolescentes, verificando possíveis infrações administrativas, ameaças e violações dos direitos das crianças e adolescentes (Presidência da República, 1990, Art. n. 95). Os psicólogos, em tal contexto, podem apoiar essas ações, auxiliando os conselheiros tutelares em seu planejamento e os acompanhando nas idas aos locais. A presença dos psicólogos nessas visitas, seguidas de supervisão técnica posterior, podem subsidiar as medidas protetivas delegadas às crianças e adolescentes em atendimento nos locais, bem como os encaminhamentos posteriores ao MP, caso verificadas irregularidades (Presidência da República, 1990, Art. n. 191). A pedido dos conselheiros tutelares, os psicólogos podem também participar de estudos de caso realizados com as equipes técnicas desses locais, seja para o tratamento de questões relacionadas às instituições, seja a seus atendidos.

A assessoria ao Poder Executivo na formulação de proposta orçamentária referente aos atendimentos a crianças e adolescentes, por meio da qual o CT atinge sua atribuição de cobrança (Presidência da República, 1990, Art. n. 136, IX), pode também ser subsidiada por psicólogos inseridos no CT. Dado o caráter intersetorial da prática psicológica no contexto das entidades de atendimento às crianças e adolescentes, o conhecimento em psicologia pode munir a proposição de propostas de políticas públicas a diversos setores. Tendo por base o conhecimento sobre as diversas possibilidades de atenção às crianças e adolescentes em diferentes contextos (Educação, Saúde, Assistência Social, etc.), os psicólogos podem auxiliar os conselheiros tutelares no mapeamento de serviços ausentes e precários no município. Também podem mapear os serviços que contribuem de forma efetiva para a promoção dos direitos das crianças e adolescentes, de forma a dar visibilidade ao que tem obtido sucesso no município. Essas ações exitosas poderiam ser multiplicadoras de metodologias para outros serviços criando uma rede de solidariedade entre os diferentes órgãos que compõem a rede. Após este mapeamento, supervisões técnicas aos conselheiros tutelates podem fundamentar as sugestões encaminhadas ao Poder 
Executivo, de modo que o CT possa participar ativamente na proposta orçamentária local.

\section{CONSIDERAÇÕES FINAIS}

O presente trabalho situou o CT como órgão administrativo autônomo, tendo por função a vigilância e garantia dos direitos das crianças e dos adolescentes. Por tal razão, são atribuições dos conselheiros tutelares a delegação de medidas protetivas e encaminhamentos jurídicos que visam a garantir o acesso de crianças e adolescentes a seus direitos. O desempenho desta função garantista delegada ao CT deve se dar, sobretudo, a partir de ações de caráter preventivo, de fiscalização e cobrança ao agente violador de direitos seja a família, a sociedade ou o Estado. Isto significa que, para além dos atendimentos individualizados prestados aos núcleos familiares que chegam ao $\mathrm{CT}$, o órgão deve se organizar em torno de ações que se antecipam às denúncias e, até mesmo, à própria violação de direitos.

Os profissionais técnicos inseridos no CT não devem se ocupar de serviços socioassistenciais ou periciais precários ou ausentes no município, mas promover ações que vão subsidiar as ações exercidas pelo órgão. A oferta desses serviços no CT desconfiguraria seu reconhecimento como órgão autônomo de função política. Ademais, a prestação de serviços psicológicos perpetuaria a violação de direitos pelo Poder Executivo local, tendo em vista que o CT legitimaria as irregularidades na prestação de serviços às crianças e adolescentes.

Foram apresentadas, assim, três possíveis atribuições dos psicólogos no CT. Por meio da capacitação e formação continuada, os psicólogos podem fomentar a discussão contínua e a troca de conhecimento acerca de diferentes temas/questões que atravessam o fazer dos conselheiros tutelares. Supervisões técnicas promovidas por psicólogos podem também subsidiar a delegação de medidas protetivas e os encaminhamentos jurídicos prosseguintes aos núcleos familiares em atendimento no CT. Além dessas atribuições, os psicólogos podem auxiliar as ações de caráter preventivo, de fiscalização e de cobrança exercidas pelos CT. Essas atribuições envolvem o apoio técnico: às campanhas educacionais realizadas pelo $\mathrm{CT}$; às atividades de fiscalização promovidas a entidades de atendimento a crianças e adolescentes; e à assessoria prestada ao Poder Executivo municipal na formulação de proposta orçamentária referente a atendimentos a crianças e adolescentes. A realização de ações como essas antecipam-se às denúncias e às próprias violações de direito.

As atribuições apresentadas encontram-se em consonância com os princípios legais que descrevem o CT como órgão autônomo de função políticoadministrativa. As ações atingem sua plenitude, assim, com base, não apenas na instrumentalização legal, mas em um conjunto de competências técnicas de psicólogos à disposição dos conselheiros tutelares. Ainda que o presente trabalho 
tenha como enfoque a inserção de psicólogos no CT, o mesmo raciocínio pode ser válido para a atuação de outros profissionais técnicos, como os assistentes sociais, pedagogos e assistentes jurídicos. Propõe-se, portanto, que, assim como estabelecido no artigo 150 do ECA (Presidência da República, 1990) a implementação de uma equipe multidisciplinar "destinada a assessorar a Justiça da Infância e Juventude", a lei deveria pressupor, em nível federal, a implementação de equipes técnicas para subsidiar as ações promovidas pelos conselheiros tutelares em seu contexto de atuação.

O ensaio teórico apresenta limitações associadas à assistematização das escolhas e análise das referências. Nesse sentido, estudos de revisão sistemática e relatos de experiências podem ser desenvolvidos futuramente como forma de prosseguir com a discussão aqui iniciada.

\section{DECLARAÇÃO DE CONFLITOS DE INTERESSE}

Não há conflitos de interesse.

\section{REFERÊNCIAS}

Alexandrino, M., \& Paulo, V. (2013). Direito administrativo descomplicado (21a Ed.). Rio de Janeiro, RJ: Forense.

Arantes, E. M. M. (2011). Pensando a psicologia aplicada à justiça. In H. S. Gonçalves, \& E. P. Brandão (Eds.), Psicologia jurídica no Brasil (3a ed., pp. 11-42). Rio de Janeiro, RJ: Nau.

Batista, D. S. M., \& Cerqueira-Santos, E. (2012). Um estudo sobre conselheiros tutelares diante de práticas de violência. Psicologia e Saúde, 4(2), 116-125.

Bazon, M. R. (2008). Violências contra crianças e adolescentes: Análise de quatro anos de notificações feitas ao Conselho Tutelar na cidade de Ribeirão Preto, São Paulo, Brasil. Cadernos de Saúde Pública, 24(2), 323-332. doi: 10.1590/S0102-311X2008000200011

Brambilla, B. B., \& Avoglia, H. R. C. (2010). O estatuto da criança e do adolescente e a atuação do psicólogo. Psicólogo InFormação, 14(1), $102-$ 121. doi:10.15603/2176-0969/pi.v14n14p102-121

Bulhões, R. R. R. (2010). Criação e trajetória do conselho tutelar no Brasil. Lex Humana, 2(1), 110-131. doi:10.14195/2175-0947_2-1_6

Câmara Municipal do Rio de Janeiro. (2001). Lei Municipal n. 3.282, de 10 de outubro de 2001. (2001, 10 de outubro). Dispõe sobre a implantação, estrutura, processo de escolha e funcionamento dos Conselhos Tutelares do Município do Rio de Janeiro. Recuperado de http://mail.camara.rj.gov.br/APL/Legislativos/contlei.nsf/50ad008247b8f03 0032579ea0073d588/2ca180c615fdb8aa032576ac0072e8aa?OpenDocumen $t$ 
Desaulniers, J. B. R. (2002). Conselho Tutelar: Uma organização emergente. In C. M. L. Nahra, \& M. Bragaglia (Eds.), Conselho tutelar: Gênese, dinâmica e tendências (pp. 27-39). Canoas, RS: ULBRA.

Deslandes, S. F., \& Campos, D. S. (2015). A ótica dos conselheiros tutelares sobre a ação da rede para a garantia da proteção integral a crianças e adolescentes em situação de violência sexual. Ciência \& Saúde Coletiva, 20(7), 2173-2183. doi:10.1590/1413-81232015207.1381

Espíndula, D. H. P., Trindade, Z. A, \& Santos, M. F. S. (2009). Representações e práticas educativas de mães referentes a filhos atendidos pelo conselho tutelar. Psicologia em Estudo, 14(1), 137-147. doi:10.1590/S141373722009000100017

Fernandes, P. V., \& Aragão, E. M. A. (2011). Peculiaridades entre conselho tutelar e crianças encaminhadas pela escola. Fractal: Revista em Psicologia, 23(1), 219-232. doi:10.1590/S1984-02922011000100015

Frizzo, K. R., \& Sarriera, J. C. (2005). O conselho tutelar e a rede social na infância. Psicologia USP, 16(4), 175-196. doi:10.1590/S010365642005000300009

Frizzo, K. R., \& Sarriera, J. C. (2006). Práticas sociais com crianças e adolescentes: O impacto dos conselhos tutelares. Psicologia: Ciência e Profissão, 26(2), 198-209. doi:10.1590/S1414-98932006000200004

Gebeluka, R. A. D., \& Bourguignon, J. A. (2010). Configuração e atribuições do conselho tutelar. Emancipação, 10(2), 551-562. doi:10.5212/Emancipacao.v.10i2.551562

Kaminski, A. K. (2002). Conselhos Tutelares: Perspectivas. In C. M. L. Nahra, \& M. Bragaglia (Eds.), Conselho tutelar: Gênese, dinâmica e tendências (pp. 133-148). Canoas, RS: ULBRA.

Ministério da Saúde. Gabinete do Ministro (2008). Portaria n. 154, de 24 de janeiro de 2008. Cria os Núcleos de Apoio à Saúde da Família - NASF. Recuperado

de http://bvsms.saude.gov.br/bvs/saudelegis/gm/2008/prt0154_24_01_2008. html

Motti, A. J. A. (2012). Programa de formação continuada para conselheiros da área da infância e juventude. Serviço Social em Revista, 15(1), 190-206. doi: 10.5433/1679-4842.2012v15n1p190

Netto, J. P. (2007). Capitalismo monopolista e Serviço Social (6a ed.). São Paulo, SP: Cortez.

Presidência da República. Casa Civil. Subchefia para Assuntos Jurídicos. (1979). Lei Federal n. 6.697, de 10 de outubro de 1979. Institui o Código de Menores. Recuperado de http://www.planalto.gov.br/ccivil_03/leis/19701979/L6697.htm 
Presidência da República. Casa Civil. Subchefia para Assuntos Jurídicos. (1988). Constituição da República Federativa do Brasil de 1988. Recuperado de http://www.senado.gov.br/sf/legislacao/const/

Presidência da República. Casa Civil. Subchefia para Assuntos Jurídicos. (1990). Lei Federal n. 8.069, de 13 de julho de 1990. Dispõe sobre o Estatuto da Criança e do Adolescente e dá outras providências. Recuperado de http://www.planalto.gov.br/ccivil_03/leis/L8069.htm

Presidência da República. Casa Civil. Subchefia para Assuntos Jurídicos. (2011). Lei Federal n. 12.435, de 6 de julho de 2011. Altera a Lei no 8.742, de 7 de dezembro de 1993, que dispõe sobre a organização da Assistência Social. Recuperado de http://www.planalto.gov.br/ccivil_03/_ato20112014/2011/lei/l12435.htm

Rizzini, I. \& Pilotti, F. (2011). A arte de governar crianças: A história das políticas sociais, da legislação e da assistência à infância no Brasil (2a ed.). São Paulo, SP: Cortez.

Sarriera, J. C. (2010). O paradigma ecológico na Psicologia Comunitária: Do contexto à complexidade. In J. C. Sarriera, \& E. T. Saforcada (Eds.), Introdução à Psicologia Comunitária: Bases teóricas e metodológicas (pp. 27-48). Porto Alegre, RS: Sulina.

Scheinvar, E. (2012). Conselho tutelar e escola: A potência da lógica penal no fazer cotidiano. Psicologia \& Sociedade, 24(n.spe.), 45-51. doi: $10.1590 /$ S0102-71822012000400008

Sequeira, V. C., Monti, M., \& Braconnot, F. M. O. (2010). Conselhos tutelares e psicologia: Políticas públicas e promoção de saúde. Psicologia em Estudo, 15(4), 861-866. doi:10.1590/S1413-73722010000400022

Souza, M. P. R., Teixeira, D. C. S., \& Silva, M. C. Y. G. (2003). Conselho tutelar: Um novo instrumento social contra o fracasso escolar? Psicologia em Estudo, 8(2), 71-82. doi:10.1590/S1413-73722003000200008

Xaud, G. M. B. (2000). Os desafios da intervenção psicológica na promoção de uma nova cultura de atendimento do adolescente em conflito com a lei. In L. M. T. Brito (Ed.), Temas de Psicologia Jurídica (2a ed., pp. 87-102). Rio de Janeiro, RJ: Relume Dumará.

Yamamoto, O. H., \& de Oliveira, I. F. (2010). Política Social e Psicologia: Uma trajetória de 25 anos. Psicologia: Teoria e Pesquisa, 26(25ANOS), 9-24. doi: 10.1590/S0102-37722010000500002 
Vinicius Coscioni é psicólogo pela Universidade Vila Velha, mestre em Psicolologia pela Universidade Federal do Espírito Santo e doutorando em Psicologia pela Universidade Federal do Rio Grande do Sul. Trabalha na linha Desenvolvimento Humano e recebe financiamento de pesquisa da CAPES.

viniciuscoscioni@gmail.com

Edinete Maria Rosa é psicóloga pela Universidade Federal do Espírito Santo, mestre em Psicologia pela Universidade Federal do Espírito Santo e doutora em Psicologia Social pela Universidade de São Paulo. É professora do Departamento de Psicologia Social e do Desenvolvimento e do Programa de Pós-Graduação em Psicologia da Universidade Federal do Espírito Santo. Trabalha nas linhas Desenvolvimento Humano e Psicologia Social e recebe financiamento de pesquisa do CNPq. edineter@gmail.com

Sabrine Mantuan dos Santos Coutinho é psicóloga pela Universidade Federal do Espírito Santo e doutora em Psicologia pela Universidade Federal do Espírito Santo. É professora do Departamento de Psicologia da Universidade Federal Fluminense e do Programa de Pós-Graduação em Psicologia da Universidade Federal do Espírito Santo. Trabalha na linha Psicologia Social. sabrinems@hotmail.com

Hildicéia Santos Affonso é psicóloga pela Faculdade de Humanidades Pedro II e mestre em administração pela Fundação Instituto Capixaba de Pesquisas em Contabilidade, Economia e Finanças. É professora do Curso de Psicologia da Universidade Vila Velha e da Faculdade Multivix. Trabalha na linha Psicologia Jurídica. hildiceia@hotmail.com

Sílvia Helena Koller é psicóloga pela Pontifícia Universidade Católica do Rio Grande do Sul, mestre em Psicologia pela Universidade Federal do Rio Grande do Sul e doutora em Educação pela Pontifícia Universidade Católica do Rio Grande do Sul. É professora do Departamento de Psicologia do Desenvolvimento e da Personalidade e do Programa de Pós-Graduação em Psicologia da Universidade Federal do Rio Grande do Sul. Trabalha na linha Desenvolvimento Humano e recebe financiamento de pesquisa do CNPq. silvia.koller@gmail.com

A contribuição de cada autor pode ser atribuída como se segue: Todos os autores contribuíram para a conceitualização, investigação e visualização do artigo; V. C. fez a redação inicial do artigo (rascunho) e as demais são responsáveis pela redação final (revisão e edição). 
Os autores agradecem à CAPES e ao CNPq pela conceção de bolsas. À CAPES pela conceção de bolsa de mestrado e doutorado ao primeiro autor e ao CNPq pela conceção de bolsa pesquisador ao segundo e quinto autor

Recebido em: 06/06/2017

$1^{\text {a }}$ revisão em: 03/12/2017

Aceito em: 24/06/2018 